\title{
Do Farmers Adopt Fewer Conservation Practices on Rented Land? Evidence from Straw Retention in China
}

Li Gao, Wendong Zhang, Yingdan Mei, Abdoul G. Sam, Yu Song, and Shuqin Jin

\author{
Working Paper 18-WP 584 \\ August 2018
}

\author{
Center for Agricultural and Rural Development \\ lowa State University \\ Ames, lowa 50011-1070 \\ www.card.iastate.edu
}

Li Gao is Assistant Professor, School of Business Administration, China University of Petroleum, Bejing, China 102249, E-mail: gaolicup@126.com.

Wendong Zhang is Assistant Professor, Department of Economics, lowa State University, Ames, IA 50011. E-mail: wdzhang@iastate.edu.

Yingdan Mei is Associate Professor, School of Business Administration, China University of Petroleum, Bejing, China 102249. E-mail: meiyingdan@vip.sina.com.

Adboul G. Sam is Professor, Department of Agricultural, Environmental and Development Economics, Ohio State University, Columbus, OH 43210. E-mail: sam.7@osu.edu.

Yu Song is Associate Professor, School of Economics and Management, Henan Agricultural University, Zhengzhou, Henan, China 450002. E-mail: Foxsong2003@126.com.

Shuqin Jin, Research Center for Rural Economy, Ministry of Agriculture, Bejing, China 100810. E-mail: jinshuqin@126.com.

This publication is available on online on the CARD website: www.card.iastate.edu. Permission is granted to reproduce this information with appropriate attribution to the author and the Center for Agricultural and Rural Development, lowa State University, Ames, lowa 50011-1070.

For questions or comments about the contents of this paper, please contact Kenneth Liao, kliao@iastate.edu

Iowa State University does not discriminate on the basis of race, color, age, ethnicity, religion, national origin, pregnancy, sexual orientation, gender identity, genetic information, sex, marital status, disability, or status as a U.S. veteran. Inquiries can be directed to the Interim Assistant Director of Equal Opportunity and Compliance, 3280 Beardshear Hall, (515) 294-7612. 
Do Farmers Adopt Fewer Conservation Practices on Rented Land? Evidence from Straw

\section{Retention in China}

\section{Abstract}

4 We examine how land tenure arrangements affect Chinese crop farmers' adoption of straw

5 retention, a key conservation practice promoted by the Chinese government in part to curb rising

6 air pollution. Using data from a 2016 farmer household survey covering 1,659 crop plots in

7 Henan Province in central China, we analyze whether farmers are less likely to adopt straw

8 retention on rented plots compared to own-contracted plots. To address the potential endogeneity

9 of the choice of renting from others, we use an instrument exploiting the role of remittance

10 income from household members migrated to cities in a bivariate probit model and a control

11 function approach, respectively. Our main results reveal that the Chinese crop farmers'

12 likelihood of adopting straw retention were almost cut in half on rented plots compared to their

13 owned plots, assuming the assumptions for biprobit or control functions hold. This suggests

14 greater attention is needed to examine the spillovers across agricultural and environmental

15 policies as China pushes for both a nationwide land rental market and more sustainable 16 agricultural practices.

17

18 Keywords: land tenure; conservation practice; control function; bivariate probit; Chinese 19 agriculture

20 JEL Codes: Q15, Q18, O13 


\section{Introduction}

22 Land tenure security is crucial in promoting the adoption of various conservation practices, 23 including conservation tillage (Lee and Stewart, 1983; Soule et al., 2000), contour farming

24 (Soule et al., 2000), conservation crops (Fraser, 2004), and stone terraces or soil bunds 25 (Gebremedhin and Swinton, 2003). Arguably, more secure land tenure, which often refers to complete, permanent, or durable ownership of farmland, leads to higher willingness to adopt conservation practices, especially those practices with long-term soil fertility benefits. This is likely because greater land tenure security increases the likelihood of farmers reaping the benefits of land investments, which are often long-term (Feder et al., 1988; Soule et al., 2000; Fraser, 2004; Kabubo-Mariara et al., 2010). Despite the perceived significance of land tenure, there is a lack of evidence of the role of land tenure security in conservation practice adoptions, especially in developing countries such as China. This, in part, results from varying definitions of land tenure security and heterogeneity in the ownership and tenure systems across different countries (Kabubo-Mariara et al., 2010).

In China, land tenure security has particular relevance because, under the current Household Responsibility System (HRS), agricultural land is owned by the collectives at the village level, and each eligible farmer household is granted a land contract right to farm a village-allocated land parcel with up to 30 years of tenure (Hu, 1997). The distinct nature of rural tenure systems confronts Chinese farmers with greater land tenure insecurity, which could potentially hinder farmers' investments in production and conservation practices, especially those with a long time 
41 horizon. For instance, researchers have found that frequent land reallocation by the village

42 collectives to accommodate a growing rural population often dampens the stability and security

43 of land tenure, resulting in a very uncertain land tenure length with an effective length of much

44 less than 30 years (Liu et al., 1998; Brandt et al., 2002; Tan et al., 2006).

In fact, since Jacoby et al. (2002), many researchers have examined the impacts of land tenure insecurity in Chinese farmers' production decisions, with a focus on input use such as

47 organic fertilizer (e.g., Jacoby et al., 2002), land use efficiency (Zhang et al., 2011; Leight, 48 2016), and forest output efficiency (Salant and Yu, 2016). In contrast, evidence of the impacts of 49 land tenure in conservation practice adoption in China is relatively scarce. Wang et al. (2010) 50 investigate the determinants of adopting conservation tillage as well as residue retention;

51 however, they do not consider land tenure as a driving factor. Liu and Huang (2013) were among

52 the first to assess how land tenure security affects conservation practice adoption and show that

53 the ownership of land is slightly positively associated with increased likelihood of using contour 54 cultivation. $^{1}$

55 However, to the best of our knowledge, no study has explicitly modeled the role of land 56 tenure in the adoption of straw retention, an increasingly important component of conservation 57 practices (Pittelkow et al., 2015). Straw retention (i.e., returning straw to the field) refers to a 58 residue management strategy of covering the crop straws on the soil surface after harvest, which 59 has been proven to improve long-term soil productivity (Lu, 2015; Wang et al., 2015), and boost

${ }^{1}$ Chinese farmers do not own the farmland. As will be discussed in detail later, the "ownership" of a plot by a farmer household in China is actually represented as the land contract right. 
60 yield (Huang et al., 2013; Wang et al., 2015). However, burning straw, which generates large

61 amounts of PM 2.5 (Tao et al., 2013; Shon, 2015; Chen et al., 2017), is still common in China

62 and has become one of its biggest environmental problems despite increased public attention,

63 fines, and penalties. In an attempt to reduce open burning of straw, thus curbing PM 2.5

64 pollution, the Chinese government has recently undertaken various measures supporting

sustainable utilization of crop residues. For instance, in May 2015, the government announced a retention adoption. The project was extended to all of China in $2016 .{ }^{2}$ In addition, we analyze land tenure insecurity in the context of new policies in which China increasingly promotes rural land transfers among farmers through a land rental market. There is a lack of understanding on whether and how farmers make production and conservation decisions differently on rented land obtained through the rental market versus their own-contracted farmland allocated by collectives. This study aims to examine whether and how land rental decisions, which are increasingly

73 prevalent under the new rural land transfer market, affect Chinese crop farmers' adoption of

74 straw retention. We hypothesize that Chinese crop farmers are less likely to adopt straw retention

75 and other conservation practices on land rented from others due to their perceived less secure

76 land tenure arrangement. We argue that farmers on rented fields face less secure land tenure due

77 to the short-term nature of leasing contracts, and thus have lower willingness to undertake a

\footnotetext{
2 The pilot project in 2015 was undertaken in five provinces-Anhui, Shandong, Hunan, Sichuan and Zhejiang. Our study analyzes crop and crop residue choices by farmers in Henan province for the 2015 growing season, which was not included in the pilot project. In addition, the progress on the subsidy project varied dramatically among different regions. Based on the experiences of our interviewers, most farmer households in Henan were not aware of this subsidy program at the time of the survey.
} 
conservation practice compared to land formally allocated to them via long-term contracts from

79 the collectives.

To test our hypothesis, we use a 2016 rural household survey covering 1,659 crop plots in

81 Henan Province in central China and analyze whether farmers are less likely to adopt straw

82 retention on rented plots compared to own-contracted plots. To address the potential endogeneity

83 of the land tenure variable, we rely on an instrument that proxies the remittance income from the

84 household members who migrated into cities. Arguably, a higher ratio of migrants' income over

85 agricultural profits, conditional on available laborers and farmers' household income, would lead

86 to a smaller likelihood of renting from others but not directly shift conservation practice choices.

87 Following Wooldridge (2010), we employ both a bivariate probit and a control function approach

88 using the above instrument to address the endogenous explanatory variable of land tenure.

89 Our main results confirmed that Chinese crop farmers are less likely to adopt straw

90 retention on fields rented from others compared to own-contracted plots. In particular, the

91 bivariate probit and control functions controlling for the endogeneity of the land tenure variable

92 suggest that on average, the likelihood of Chinese crop farmers adopting straw retention on

93 rented fields are almost only half compared to that for their own-contracted fields. In contrast,

94 simple probit regressions with endogenous land tenure variable show that a rented plot is

95 associated with an eight percent reduction in the probability of adopting straw retention after

96 harvest throughout 2015. Overall, our results confirm our hypothesis of less conservation

97 practice adoption given less secure land tenure arrangements, and are comparable to many 
studies in other countries.

This study contributes to the literature of conservation practice adoption by quantitatively examining the link between land tenure security and straw retention adoption in China for the first time. In particular, our analysis provides evidence that Chinese crop farmers are significantly less likely to adopt straw retention, a critical conservation practice, on rented plots compared to those own-contracted plots. More importantly, our research is of great policy relevance since it reveals the previously overlooked, potentially negative interconnection between two policies promoted by the Chinese government-encouraging the adoption of straw retention and expanding the rural land rental market-and offers insights into how the government can better promote and balance them. Finally, the significant larger average partial effect in the main specifications suggests that one needs to control for the endogeneity of the land tenure variable using the biprobit or control function approach.

111 land system and the development of the land rental market. Section 3 introduces the conceptual

112 framework. Section 4 introduces the empirical implementation strategy. Section 5 describes the 113 data used in this study and empirical implementation. Section 6 discusses the empirical results. 114 Section 7 provides concluding remarks.

\section{2. Land Tenure and Land Rental Market in China}

116 China prohibits private land ownership. The current HRS was introduced in the early 1980s and 
117 allocates a parcel of contracted farmland to each eligible rural household on the basis of 118 household size, which is referred to as the land contract (and use) right. Nevertheless, the 119 allocated land is owned by village collectives represented by villager committee or township 120 government $(\mathrm{Hu}, 1997)$. Farmers are free to make their own agricultural production decisions, 121 though they are not permitted to convert the land to non-agricultural use. In the early stages of 122 HRS, land contracts only lasted for a one- or two-year period, which led to significant land 123 tenure insecurity and discouraged farmers from making land improvements (Krusekopf, 2002). 124 Realizing this limitation, the Chinese government lengthened the land contract terms to 15 years, 125 further extending it to 30 years in 1993 (Zhang et al., 2011).

127 security for rural households for two reasons: (a) village collectives periodically reallocate 128 village land through administrative means to reach egalitarian goals in response to household 129 demographic changes, even in the midst of land contract periods (Liu et al., 1998; Brandt et al., 130 2002; Tan et al., 2006); and, (b) collective allocations efficiency is negatively impacted by an 131 increasing number of rural migrants going off-farm and working outside the village, which tends 132 to lead to productive inefficiency (Benjamin and Brandt, 2002).

133 In response to the rising need of more secure land tenure, the central government has 134 codified a framework for the protection of land rights and development of a land rental market, 135 including the Land Management Law (1998), the Rural Land Contracting Law (2003), and the 136 Property Law (2007). Subsequently, the land rental market took off rapidly, with a participation 
rate of about 10 percent in 2001 (Deininger and Jin, 2005), and stayed around that level for

138 almost a decade. However, in many areas, farmland continued to be illegally reallocated by local

139 officials (Zhang et al., 2011). With the steady increase in the number of rural workers migrating

140 to urban regions, more and more rural households no longer have the need to keep all contracted

141 land due to lack of laborers, which to a large extent stimulates the development of a rural rental

142 market. Figure 1 shows the national growth of transferred rural land in China. The percentage of

Figure 1. Scale of land Transfers in China, 2008-2015.

148 (Source: Author’s calculation; Ye, 2015; Ministry of Agriculture, 2014, 2015, 2016) 
152 collective land ownership, the government allows rural households to lease out the land use right

153 while maintaining the original land contract with the village government, which is largely to

154 stimulate land transfer through the rental market. ${ }^{3}$ However, the decomposition of rural land

155 rights may raise a further question. The transferred land use right, which depends on how the

156 leasing contract is made between rural households, may not be as secure as the land contract

157 right.

158

159

160

161

162

163

164

165

166

167 Following previous works by McConnell (1983) and Soule et al. (2000), we develop a 168

While rural land transfer allows more flexible allocation of farmland across farmers, potentially moving from inefficient producers to more efficient producers, it remains uncertain how the tenants, who obtained the farmland via the rural land transfer market for a finite amount of time, would treat these land parcels differently compared to those owned and operated by its original contractees. Enlightened by previous literature on limited investments on rented land (Soule et al., 2000; Fraser, 2004; Kabubo-Mariara et al., 2010), we assume that tenants of rented land would have less incentive to make long-term investments, such as adopting conservation practices (i.e., straw retention) on these parcels.

\section{Conceptual Framework} three-stage model to analyze the adoption behavior of straw retention under different land tenure arrangements.

\footnotetext{
3 See the 2014 No. 1 Policy Document available at http://www.moa.gov.cn/zwllm/zwdt/201401/t20140120_3742582.htm (in Chinese).
} 
171 household decides on the treatment of crop residues (straws), which involves a treatment cost

172 denoted by $C_{j}$. In this context, we designate $j=s$ for adopting straw retention and $j=n$ for

173 non-adoption. Straw retention requires straws to be smashed before they are covered and mixed

174 with the soil surface, which takes additional machinery or labor costs and thus $C_{s}>0$. If straws

175 are not returned to the fields, farmers can either burn, discard, or use straws for other off-farm

176 purposes such as feed, fuel, and to sell. Any of these treatments may also involve some costs

177 including collecting, storing, and transporting of straws and thus $C_{n}>0$. It is difficult to

178 determine which of $C_{s}$ and $C_{n}$ is higher, as $C_{j}$ depends on specific straw treatment as well as

179 the crop type.

Straw treatment in the first stage will also affect farming for the next season. Let $\pi_{j}$ be the

second-season net returns under first-stage straw treatment, $j$. Although straws can improve soil quality, acting similar to fertilizer, it takes time for straw to decay, which may affect the next cropping given that farmers are often time-pressed between harvesting and sowing (Peng et al., 2016; Zhang et al., 2017), especially during autumn and in double-crop rotation areas like Henan 
190 farmland, denoted by $V_{j}$. Research has shown that straw retention can help reduce soil erosion 191 and improve fertility and productivity over time, thus better retaining the long-term value of the 192 land. Therefore, $V_{s}>V_{n}$.

193 Assume that a farmer household (either contractee or renter) selects a straw treatment 194 option, $j$, to maximize the present value, $P V_{j}$, of the three terms previously discussed on a 195 cultivated plot (either own-contracted or rented), as shown by the following equation:

$$
\max _{(j)} P V_{j}=\pi_{j}-C_{j}+\lambda V_{j} /(1+r)^{T}
$$

197 where $r$ represents the discount rate and $T$ the number of periods. Following Soule et al. 198 (2000), $\lambda$ is included as a tenure-security indicator weighting the third term that measures the 199 farmer household's belief about its ability to use or sell the land in the future. Therefore, the 200 more secure the land tenure, the higher $\lambda$ and greater importance of the long-term land value in 201 the household's decision-making process.

202 Based on equation (1), it is optimal for a rational farmer household to adopt straw retention 203 when

$$
\pi_{s}-C_{s}+\lambda V_{s} /(1+r)^{T}>\pi_{n}-C_{n}+\lambda V_{n} /(1+r)^{T}
$$

205 or

$$
\lambda \Delta V / R>\Delta \Pi
$$

207 where $\Delta \Pi=\left(\pi_{n}-C_{n}\right)-\left(\pi_{s}-C_{s}\right), \Delta V=V_{s}-V_{n}$ and $R=(1+r)^{T}$. Since $V_{s}>V_{n}$ and $R$ 
208 is positive, condition (3) actually suggests that the adoption of straw retention hinges on whether 209 the potential short-term profit loss (i.e., the right-hand side) can be offset by the perceived gains 210 in long-term land value (i.e., the left-hand side). That is, with higher $\lambda$, or more secure land 211 tenure, the farmer household is more likely to undertake long-term improvement activities such 212 as straw retention, as stated in our hypothesis.

An empirical estimate of the value of $\lambda$ is lacking. In countries where private land ownership is well-established, it is plausible to assume that $\lambda=1$ for a land owner. While in the context of China, the corresponding “owner” of farmland may be the contractee who bears both the land contract and use rights. The value of $\lambda_{\text {contractee }}$ is possibly lower than, but close to 1 , 217 since land contractees are also confronted with tenure insecurity such as land reallocation. For 218 renters, $\lambda$ should be much lower since they only possess the land use right and are mainly 219 concerned with short-term profits. However, $\lambda_{\text {renter }}$ could be higher than zero if renters can continually use the land, which depends on the duration of the lease. In this case, more than 90 221 percent of the existing leases in the study region are oral and informal on a one-year basis. Thus,

222 we hypothesize that $\lambda_{\text {renter }}<\lambda_{\text {contractee }}$ or the probability of adopting straw retention is 223 higher for contractees than for renters, which we test in our empirical model.

\section{4. Empirical Implementation}

\section{$225 \quad$ 4.1. Base probit model}

226 To test the above hypothesis, we first employ a binary discrete choice model derived from the 
227 latent variable approach. Let $y$ denote a farmer household's decision to adopt straw retention or 228 not, which is generated from a latent variable, $y^{*}$, equal to $\lambda \Delta V / R-\Delta \Pi$ from equation (3).

229 The difference between short-term profits and long-term land values for the farmer household is 230 unobserved, but one can observe the household's adoption decision. If $y^{*}$ is positive, straw 231 retention is adopted and $y=1$ is observed; otherwise, $y=0$ is observed if $y^{*}$ is negative.

232 For each household, $i$, the latent variable $y_{i}^{*}$ is assumed to be a linear function of the 233 vector of observable household, plot, and regional characteristics $\left(\mathbf{X}_{i}\right)$ as follows:

$$
y_{i}^{*}=\boldsymbol{\beta} \mathbf{X}_{i}+\varepsilon_{i},
$$

where $\boldsymbol{\beta}$ is the coefficient vector and $\varepsilon_{i}$ a random error term. The linkage between $y_{i}^{*}$ and $y_{i}$ 236 is as follows:

$$
y_{i}=\left\{\begin{array}{l}
1, \text { if } y_{i}^{*}>0 \\
0, \text { if } y_{i}^{*}<0
\end{array}\right.
$$

then the probability that household $i$ adopts straw retention $\left(y_{i}=1\right)$ is given by

$$
\begin{aligned}
\operatorname{Pr}\left[y_{i}=1\right] & =\operatorname{Pr}\left[y_{i}^{*}>0\right] \\
& =\operatorname{Pr}\left[\boldsymbol{\beta} \mathbf{X}_{i}+\varepsilon_{i}>0\right] \\
& =1-\operatorname{Pr}\left[\varepsilon_{i} \leq-\boldsymbol{\beta} \mathbf{X}_{i}\right] \\
& =F\left(\boldsymbol{\beta} \mathbf{X}_{i}\right),
\end{aligned}
$$


$k$, is assumed to be written as:

$$
\operatorname{Pr}\left[\operatorname{adopt}_{i k}=1\right]=\operatorname{\theta rent}_{i k}+\boldsymbol{\beta} \mathbf{X}_{i k}+u_{i k}
$$

where $a_{d o p t} t_{i k}$ represents the adoption dummy, which equals unity if the household $i$ adopts

straw retention on plot $k$; rent ik $_{i k}$ is a land tenure dummy, which equals unity if the plot is

rented from others, and is designed to capture the land tenure insecurity denoted earlier as

$\lambda_{\text {renter }} ; \mathbf{X}_{i k}$ is the vector of other plot-level and household-level control variables; and, $u_{i k}$ is

252 the error term. $\hat{\theta}$ is of primary interest because it measures the marginal effect of renting from others on the adoption of straw retention.

The land tenure dummy may be endogenous to adoption decisions for several reasons. First, growers on rented plots may self-select into non-conservation activities. For instance, renters could be large-scale producers who are keener to maximize profits on all grounds (including rented plots) and thus are more cognizant of all possible cost savings and prone to select the profit-maximizing practice. ${ }^{4}$ Given that air quality impacts from straw burning is currently external to a producer's decision process, the renters are more likely to adopt the least costly option as opposed to more costly straw retention. In this case, the naïve probit estimate of the

\footnotetext{
${ }^{4}$ As indirect evidence to support the claim that renters are probably large-scale producers, we make a simple statistic for our surveyed sample. Of all 670 valid households, 588 households are purely own-contractees, which means they only cultivate on their own contracted plots throughout 2015; the remaining 82 households have rented plots to cultivate besides their own-contracted plots. The average area of cultivable land in 2015 for 82 renters is $16.06 \mathrm{Mu}$, about four times larger than that of 588 purely own-contractees, which is only $4.86 \mathrm{Mu}$.
} 
262 are correlated with both adoption choices and rental decisions, including on-farm characteristics 263 such as land shapes, soil quality and machinery use, and off-farm factors such as 264 government-supported agricultural policies.

265 Technically, the endogeneity arises due to the presence of correlation between rent $_{i k}$ and

$266 u_{i k}$, which may bias the estimate of $\hat{\theta}$. In order to obtain a consistent $\hat{\theta}$, we further consider two 267 approaches separately dealing with the endogeneity issue, a bivariate probit model and a control 268 function method.

\subsection{Bivariate probit model}

270 The bivariate probit model is frequently used in estimating the effect of an endogenous binary

271 treatment on a dichotomous outcome, while accounting for unobserved confounders

272 (Wooldridge, 2010). For expositional purposes, we rewrite the adoption equation and construct

273 the two-equation latent variable framework as follows:

$$
y^{*}=x^{\prime} \beta+\theta d^{*}+u, y=1 \text { if } y^{*}>0
$$

$$
d^{*}=z^{\prime} \gamma+\varepsilon, d=1 \text { if } d^{*}>0
$$

276 where $y^{*}$ and $d^{*}$ represent the latent outcome (i.e., adoption) and treatment (i.e., renting) 277 variables, respectively; $x$ and $\mathrm{z}$ are covariates in each equation; and, $u$ and $\varepsilon$ are 278 corresponding errors. We assume that households' rental decisions are endogenous to straw 279 retention adoption, thus $\varepsilon$ is correlated with $u$. The bivariate probit builds on the assumption 280 that $(u, \varepsilon)$ follows a bivariate standard normal joint distribution with zero means, unit 
variances, and correlation coefficient $\rho$ (i.e., $\rho=\operatorname{corr}(u, \varepsilon)$ ):

$$
(u, \varepsilon) \sim N\left(\left[\begin{array}{l}
0 \\
0
\end{array}\right],\left[\begin{array}{ll}
\rho & 1 \\
1 & \rho
\end{array}\right]\right)
$$

To identify the parameters $\theta$ and $\beta$ in the adoption equation, the covariates $z$ in equation (9) must contain at least one variable as an instrument for $d^{*}$ (or exclusion restriction) not included in covariates $x$ in equation (8). Otherwise, simply relying on nonlinearities without excluded instruments will lead to ill specification and the estimated partial effects may also be biased (Altonji et al., 2005; Wooldridge, 2010).

In particular, we construct a ratio of annual income for a family’s migrant workers to annual agricultural profits for the farmer household as the instrument for the rental variable. The higher the ratio, the higher the remittances the family receives from migration than from farming, and thus a smaller likelihood that the household would rent more farmland from other contractees. The idea is that the ratio serves as a proxy of a household's ability to earn additional income from urban employment and thus is directly associated with household's rental decisions. It is 294 possible that the migrants' income ratio is still endogenous to adoption because higher remittances means a lack of labor supply available for agricultural production, or more money to 296 potentially buy straw retention machinery. In other words, the ratio may affect the adoption 297 choice through laborer numbers or gross household income. Empirically, this can be overcome 298 by including these two variables as controls. ${ }^{5}$ That way, the ratio variable is exogenous to

\footnotetext{
${ }^{5}$ In our empirical models, as will be noted later, the number of laborers that engaged in farming activities and annual family income will be included as control variables in all regressions.
} 
299 adoption conditional on available laborers and household income.

\subsection{Control function method}

301 The control function method addresses the endogeneity problem by directly augmenting the generalized residuals in the outcome equation, which accounts for any correlation between $d^{*}$ and $u$. Specifically, we can rewrite equation (8) as:

$$
y^{*}=x^{\prime} \beta+\theta d^{*}+\mu \tilde{\varepsilon}+v,
$$

where $\tilde{\varepsilon}$ is the fitted residuals from equation (9) and identified as the inverse Mills ratio for the whole sample, which takes the form (Gourieroux et al., 1987; Vella, 1998):

$$
\tilde{\varepsilon}=d *\left[\frac{\phi\left(z^{\prime} \widehat{\gamma}\right)}{\Phi\left(z^{\prime} \widehat{\gamma}\right)}\right]+(1-d) *\left[\frac{-\phi\left(z^{\prime} \widehat{\gamma}\right)}{1-\Phi\left(z^{\prime} \hat{\gamma}\right)}\right]
$$

308 where $d$ is the rental dummy; $\hat{\gamma}$ denotes the estimated parameter vector for the probit

309 estimation of equation (9); and, $\phi(\cdot)$ and $\Phi(\cdot)$ are normal density and normal distribution 310 functions.

Following Vella (1998), a consistent estimate of $\hat{\theta}$ can be obtained from regressing equation (11) by linear probability model (LPM), assuming the generalized residuals, $\tilde{\varepsilon}$, has

313 fully removed any correlation between $d^{*}$ and the new error $v{ }^{6}$ Although technically one 314 could rely on the nonlinearity of the probit model in the first stage of the control function 315 approach, Wooldridge has forcefully argued that it is better to have more independent variation 316 in the generalized residuals with inclusion of instrumental variables (Wooldridge, 2010, p.599).

${ }^{6}$ For detailed discussions about why equation (11) is required being estimated by LPM and characteristics of the generalized residuals, see Vella (1998). 
317 As a result, we rely on the migrants' income ratio in the first stage of the control function 318 approach when generating the generalized residuals. It is important to note that the control 319 function method with binary endogenous explanatory variables in nonlinear models is more controversial, because it requires nonstandard assumptions including that the generalized residuals act as a kind of sufficient statistic for capturing the endogeneity of the land tenure variable (Wooldridge, 2015). However, these assumptions are no more or less general than the bivariate probit assumptions (Wooldridge, 2015). In addition, equation (11) itself can serve as an endogeneity test of the binary treatment variable, the rental dummy in our model, and as an analogue of the Rivers-Vuong approach, which deals with a continuous endogenous variable in a binary response model (Rivers and Vuong, 1988). ${ }^{7}$ Specifically, rejection of the null hypothesis that $\mu=0$ in equation (11) implies that $d$ is endogenous. a control function method - to quantify the marginal effect of rental decision on straw retention adoption after controlling for the endogeneity of the land tenure variable.

\section{Data Description}

The data used in this study is drawn from a rural household survey conducted by Henan

\footnotetext{
7 In Rivers-Vuong's two-step approach, first run an OLS of the endogenous continuous variable, say $y_{2}$, on covariates $z_{2}$ and obtain the residuals $\hat{v}$; then run the probit of the binary outcome variable, say $y_{1}$, on covariates $z_{1}, y_{2}$ and $\hat{v}$. While in our model, the first-stage regression is probit and the second-stage is OLS but with generalized residuals.
} 
334 China. Henan is also a big crop straw producer, accompanied by severe air pollution resulting 335 from straw burning in open fields (Fu et al., 2017).

We have followed a stratified sampling approach in collecting our sample: for each of the

33717 prefecture cities in Henan province, we randomly selected two to four counties, and within

338 each county, we randomly selected one or two villages among the agriculturally significant

339 counties based on historical planting area. About 50 trained undergraduate research assistants

340 went to these sampled villages for face-to-face interviews of farmers. With the help of local

341 village and county officials, we randomly selected 10 percent of rural households within each

342 village based on the household registry roster. In total, our sample consists of 670 valid rural

343 household responses spanning across 175 villages in 47 counties (see Figure 2).

The household-level data covers detailed information about agricultural production and operation throughout 2015, as well as household and personal characteristics (see Appendix 1 for the full version of the questionnaire). We also supplement the survey data with climatic

347 information obtained from the National Meteorological Information Center (NMIC), which reports county-level historical averages for climate variables from 1981 to 2000 in Henan

349 Province. ${ }^{8}$

In our study area, many farmers grow at least two crops every year, typically corn during the autumn season (from June to October) and winter wheat during the winter season (from

352 October to June). As a result, farmers face two annual straw retention choices. To better identify

\footnotetext{
8 As mentioned earlier, since Henan province is not included in the pilot project for a straw retention subsidy, in our study area for the 2015 crop year, there is no subsidy available for farmers specifically targeted to incentivize straw retention.
} 
353 the impact of tenure, we treat straw retention choices for these crops separately and our unit of observation is at the plot-level for each season, with each representing a particular crop for a particular growing season.
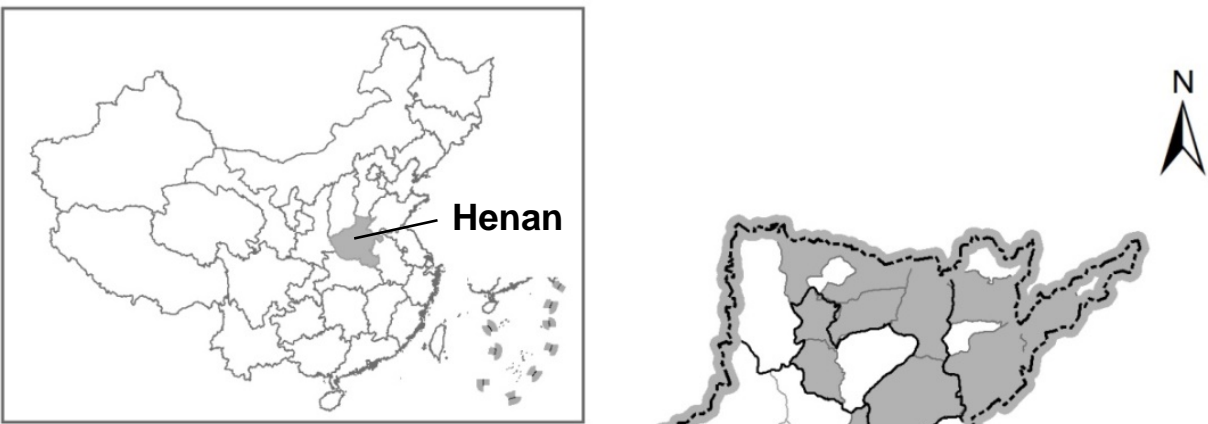

\section{$\hat{N}$}

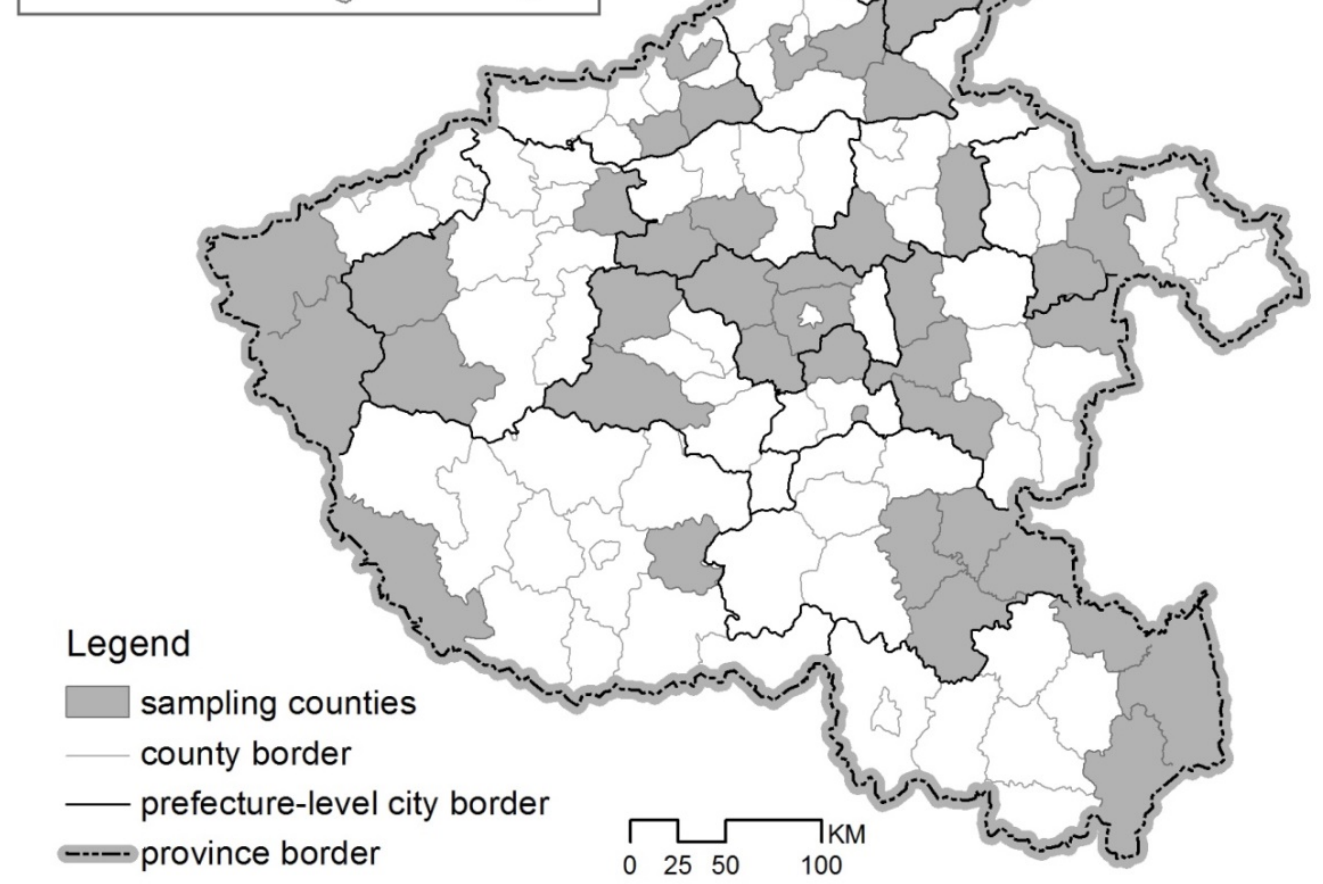

Figure 2. Map of Henan Province in China, the sampled region.

For each specified plot, the farmer is asked how he or she dealt with the straws after harvest and asked to choose among the following options: straw retention, burn, use for fuel, use for 
percent of plots are rented and 90.7 percent are own-contracted, but the areas of rented plots

account for 20.3 percent of total cultivated land areas in our sample. In addition, 70.8 percent of

plots adopted straw retention, 44.1 percent are wheat plots, 38.4 percent are corn plots, and 17.5

percent are other crops including rice, soybean, peanuts, cotton, etc.

others. Own-contracted refers to plots with current growers that are the original contractees of

(b) plots where the planted crops do not generate straws, and thus do not involve any treatment

\footnotetext{
${ }^{9}$ The survey does not collect information about the shares of straws for different straw treatments.

10 Due to widely used informal contracts between farmer households in most cases, it is not clear how the decision is made on a rented plot in this context. The decision-making process has been shown crucial in affecting adoption of conservation practices (Soule et al., 2000; Kurkalova et al., 2006). For instance, in the United States, there are two types of land renter: share-renters' decisions may be affected by land owners because both the owners and renters share the revenues and costs of production; cash-renters, however, may behave more independently since they only pay a fixed rent to the landlords while the owners do not participate in any activities. Failure to consider the differences in decision-making process may obscure the effect of land tenure on adoption.

11 Besides migrant income and agricultural profits, the annual household income also includes income from off-farm business or employment, transfer income such as pensions and government subsidies, etc. Statistics from our survey reveals that migrants'
} 
378 specifically, the annual migrant income is calculated by the number of family migrant members

379 working outside the village, times the average working months, times the average monthly

380 wages. The annual agricultural profits are simply the profits of planting crops for the whole

381 family. All this information has been collected through the survey.

We follow the extant literature of soil conservation practices in selecting other control

variables of farmer and field characteristics (Feder et al., 1988; Fox et al., 1991; Knowler and

Bradshaw, 2007; Baumgart-Gets et al., 2012; Zhang et al. 2016). Table 1 shows the descriptions

of selected variables. First, we include three farmer characteristics of the household head (who is

also the main operator): age, years of farming, and risk preference. ${ }^{12}$ Farmers with more

experience and more risk-taking attitudes are expected to have a higher likelihood of adopting

conservation practices. A second set of variables control for household-level characteristics,

which include highest years of education of all household members, number of laborers, family

income, participation in agricultural economic organization, and purchase of agricultural

insurance. We hypothesize that a richer, well-connected farmer household with better education,

income and agricultural profits jointly account for about 75 percent of gross household income on average.

12 The household head's attitude towards risk is measured through response to a binary question "whether you will utilize a newly developed fertilizer that may increase yields but has not been used yet" and is assigned "risk-seeking” if answering "yes" and "risk averse" otherwise. 
most of our study area is flat and thus we do not expect significant within-province variation.

Table 1. Descriptions of Selected Variables

\begin{tabular}{|c|c|}
\hline Variable & Description \\
\hline Straw retention & Straw retention is adopted in the plot $(1=$ yes, $0=$ no $)$ \\
\hline Rented plot & The plot is rented from other contractees $(1=$ yes, $0=$ no $)$ \\
\hline Age & Age of the household head \\
\hline Farming experience & Number of farming years of the household head \\
\hline Risk preference & Risk preference of the household head ( 1 =risk seeking, $0=$ risk averseness) \\
\hline Education & Highest years of education of all household members \\
\hline Number of laborers & Number of laborers that engaged in farming activities in 2015 \\
\hline Income & Household annual income in 2015 (10,000 Yuan) \\
\hline Organization & The household has participated in rural economic organization $(1=y e s, 0=$ no) \\
\hline Insurance & The household has purchased agricultural insurance $(1=$ yes, $0=$ no) \\
\hline Plot size & Plot area (mu=0.0667 hectares) \\
\hline Mig-ag ratio & $\begin{array}{l}\text { Ratio of annual income for family’s migrant workers to annual agricultural profits for } \\
\text { the farmer household in } 2015\end{array}$ \\
\hline July temperature & $\begin{array}{l}\text { Average daily temperature of July days from } 1981 \text { to } 2000 \text { of the county that the } \\
\text { household locates }\left({ }^{\circ} \mathrm{C}\right)\end{array}$ \\
\hline July precipitation & Average annual daily precipitation of July days from 1981 to 2000 (mm) \\
\hline Winter season & The plot is cultivated in the winter season ( $1=$ =winter season, $0=$ autumn season) \\
\hline Wheat & The plot is planted wheat $(1=$ yes, $0=$ no $)$ \\
\hline Corn & The plot is planted corn $(1=$ yes, $0=$ no $)$ \\
\hline Other crop & The plot is planted other crops $(1=$ yes, $0=$ no) \\
\hline
\end{tabular}

Table 2 shows summary statistics for the selected variables used in our model by tenure 
405 own-contracted plots, confirming our general expectation. It is worthwhile to note that the

406 instrumental variable - the migrants' income ratio on rented plots - is significantly less than that

407 on own-contracted plots, which is in line with our assumption that higher remittances from

408 migration decrease the probability of renting. Another notable fact is that rented plots are

409 generally (3.56 mu) larger in size, which provides partial evidence that renters are probably

410 large-scale producers. Other factors with significant differences include age, education,

411 household income, etc.

412

413 Table 2. Summary Statistics of Selected Variables by Tenure Type

\begin{tabular}{|c|c|c|c|c|c|c|c|}
\hline \multirow{2}{*}{ Variable } & \multicolumn{2}{|c|}{ All plots } & \multicolumn{2}{|c|}{ Own contracted plots } & \multicolumn{2}{|c|}{ Rented plots } & \multirow{2}{*}{$\begin{array}{l}\text { T-test of } \\
\text { mean diff }\end{array}$} \\
\hline & Mean & Std. Dev. & Mean & Std. Dev. & Mean & Std. Dev. & \\
\hline Straw retention & 0.708 & 0.45 & 0.712 & 0.45 & 0.665 & 0.47 & -0.048 \\
\hline Rented plot & 0.093 & 0.29 & - & - & - & - & - \\
\hline Age & 44.28 & 11.76 & 44.08 & 11.93 & 46.28 & 9.71 & $2.20^{* *}$ \\
\hline Farming experience & 28.28 & 13.59 & 28.32 & 13.55 & 27.92 & 14.04 & -0.40 \\
\hline Risk preference & 0.679 & 0.47 & 0.676 & 0.47 & 0.710 & 0.46 & 0.034 \\
\hline Education & 12.40 & 3.58 & 12.32 & 3.59 & 13.20 & 3.47 & $0.88 * * *$ \\
\hline Number of laborers & 2.611 & 1.26 & 2.620 & 1.27 & 2.516 & 1.21 & -0.104 \\
\hline Income & 4.201 & 3.15 & 4.087 & 2.96 & 5.351 & 4.48 & $1.26 * * *$ \\
\hline Organization & 0.041 & 0.20 & 0.041 & 0.20 & 0.039 & 0.19 & -0.003 \\
\hline Insurance & 0.129 & 0.34 & 0.116 & 0.32 & 0.258 & 0.44 & $0.14^{* * *}$ \\
\hline Plot size & 4.135 & 4.25 & 3.802 & 2.61 & 7.363 & 10.80 & $3.56 * * *$ \\
\hline Mig-ag ratio & 6.703 & 11.54 & 6.896 & 11.83 & 4.829 & 8.02 & $-2.07 * *$ \\
\hline July temperature & 26.98 & 0.36 & 26.97 & 0.36 & 27.05 & 0.34 & $0.08 * * *$ \\
\hline July precipitation & 337.6 & 70.4 & 336.5 & 67.7 & 348.2 & 92.0 & $-11.74 * *$ \\
\hline Winter season & 0.461 & 0.50 & 0.463 & 0.50 & 0.439 & 0.50 & -0.024 \\
\hline Wheat & 0.441 & 0.50 & 0.443 & 0.50 & 0.413 & 0.49 & -0.031 \\
\hline Corn & 0.384 & 0.49 & 0.387 & 0.49 & 0.355 & 0.48 & -0.032 \\
\hline Other crop & 0.175 & 0.38 & 0.170 & 0.38 & 0.232 & 0.42 & $0.06 *$ \\
\hline Observations & \multicolumn{2}{|c|}{1659} & \multicolumn{2}{|c|}{1504} & \multicolumn{2}{|c|}{155} & \\
\hline
\end{tabular}

Note: $* * *, * *$, and $*$ represent significance at $1 \%, 5 \%$, and $10 \%$ level, respectively. 


\section{Empirical Results}

\subsection{Base probit regressions with an endogenous regressor}

416

417

418

419

420

421

422

423

424

425

426

427

428

429

430

431

432

433 
Table 3. Results of the Binary Probit Regressions (Dependent: Adoption=1)

\begin{tabular}{cccc}
\hline Variable & $\begin{array}{c}\text { (1) Full sample } \\
\text { Marg. eff. }\end{array}$ & $\begin{array}{c}\text { (2) Own contracted } \\
\text { Marg. eff. }\end{array}$ & $\begin{array}{c}\text { (3) Rented } \\
\text { Marg. eff. }\end{array}$ \\
\hline Rented plot & $-0.0819^{* *}$ & & \\
Age & -0.0021 & $-0.0036^{*}$ & 0.0068 \\
Farming experience & 0.0002 & 0.0013 & -0.0035 \\
Risk preference & 0.0349 & 0.024 & 0.0903 \\
Education & $0.0166^{* * *}$ & $0.0147^{* * *}$ & $0.0274^{* *}$ \\
Number of laborers & $0.0659^{* * *}$ & $0.0635^{* * *}$ & $0.1041^{* * *}$ \\
Income & 0.0054 & 0.0056 & -0.0013 \\
Organization & $0.1853^{* *}$ & $0.1986^{* *}$ & 0.1909 \\
Insurance & $0.1239^{* * *}$ & $0.1380^{* * *}$ & 0.0842 \\
Plot size & $0.0093^{* *}$ & $0.0122^{* *}$ & 0.0027 \\
July temperature & $-0.0792^{*}$ & -0.1153 & 0.1766 \\
July precipitation & $0.0013^{* * *}$ & $0.0013^{* * *}$ & $0.0011^{* *}$ \\
Winter season & $0.1284^{* *}$ & $0.1600^{* *}$ & 0.0176 \\
Crop dummies & & & \\
Observations & Yes & 1659 & Yes \\
\% correctly predicted & 0.8005 & 0.8005 & 1659 \\
LR test (p-value) & & $\chi^{2}(14)=30.06(0.0075)$ & \\
\hline
\end{tabular}

Note: ${ }^{* * *}, * *$, and $*$ represent significance at $1 \%, 5 \%$, and $10 \%$ level, respectively. Standard errors are clustered at the household level. The marg. eff. columns report the average partial effects across all individuals in the sample. The null of the likelihood ratio test is no systematic difference in coefficients across tenure types.

437 "rented plot" dummy is negative and significant at the five percent level, and shows that a rented 438 plot is associated with about eight percent lower probability of adopting straw retention than an 439 own-contracted plot, ceteris paribus. The result confirms our hypothesis and is consistent with 440 previous studies regarding the impacts of land tenure on conservation practice adoption (Soule et 441 al., 2000; Fraser, 2004; Kabubo-Mariara et al., 2010). The household-level characteristics appear 
442 to be more important in the adoption decision-higher educational attainment, greater number of 443 laborers, participation in an agricultural economic organization, and purchase of agricultural 444 insurance are significantly and positively related to increased likelihood of adoption. More 445 specifically, each extra year of education increases the probability of adoption by about two 446 percent and one more laborer leads to an increase of the likelihood of adoption by about seven 447 percent. Participation in agricultural economic organization and purchase of agricultural 448 insurance have a larger effect on adoption, with values of about 19 percent and 12 percent, 449 respectively. Two climate variables are significant, suggesting that straw retention occurs more 450 frequently where the climate is warmer and wetter (more rain). The estimated coefficient of plot 451 size indicates that one more unit increase of plot size results in an about one percent increase of 452 the likelihood of adoption, which reflects that larger farmland in fact lowers the average cost of 453 adoption. The positive and significant winter dummy verifies the existence of seasonal effect on 454 residue management. We also examine whether the estimated coefficients systematically differ by tenure type. We conduct separate probit regressions for each of the two tenure categories, own-contracted and 457 rented plots, with all other independent variables the same as those in the full-sample regression. 458 A Chi-square statistic of 30.06 in the likelihood ratio test rejects the null hypothesis that the 459 coefficients are identical across tenure types, implying that the impact of all other characteristics 460 on adoption of straw retention relies on the specific tenure status of the plot. ${ }^{13}$ The resulting

\footnotetext{
13 In conducting the likelihood ratio test, we do not specify clustered standard errors at any level in the regressions.
} 
coefficients and average partial effects by tenure type are reported in columns (2) and (3) in

Table 3, which shows that despite similarity in other variables, the age of household head, organization participation, purchase of insurance, plot size, and seasonal effect only matter for own-contracted plots, while they have no effect on adoption for rented plots. The sharp disparity reflects a significantly different decision mechanism for a renter in adopting straw retention. Although the simple probit models shown in Table 3 provide suggestive evidence of the negative impacts of land rental decisions on straw retention adoptions, it is important to note that the key variable of interest, the land rental variable, is potentially endogenous and thus the estimates might be biased.

\subsection{Results of bivariate probit model and control function method}

To control for or mitigate the endogeneity of the rental variable, we also employ two alternative approaches - a bivariate probit and a control function method with a linear probability model. In both models, the ratio of migrants' income to agricultural profits for the farmer household is used as the instrument. ${ }^{14}$ Results are reported in Tables 4 and 5, respectively.

\footnotetext{
14 We have also tried "migrants' income in levels" and "relative share of migrants' income” as exclusion restrictions. Results are very similar, but using the ratio variable as the restriction has the best fits. Regression results for bivariate probit and control function method using the other two restrictions are available from authors upon request.
} 
Table 4. Results of Bivariate Probit Model

\begin{tabular}{|c|c|c|c|c|}
\hline \multirow{2}{*}{ Variable } & \multicolumn{2}{|c|}{ Adoption Equation } & \multicolumn{2}{|c|}{ Renting Equation } \\
\hline & Marg. eff. & p-value & Coef. & p-value \\
\hline Rented plot & $-0.5113^{* * *}$ & 0.000 & & \\
\hline Age & -0.0008 & 0.547 & $0.0187 * * *$ & 0.004 \\
\hline Farming experience & -0.0006 & 0.603 & $-0.0107 * *$ & 0.034 \\
\hline Risk preference & $0.0353^{*}$ & 0.070 & -0.0377 & 0.699 \\
\hline Education & $0.0165^{* * *}$ & 0.000 & $0.0276^{* *}$ & 0.037 \\
\hline Number of laborers & $0.0585^{* * *}$ & 0.000 & -0.0597 & 0.119 \\
\hline Income & $0.0064 * *$ & 0.043 & $0.0301^{* *}$ & 0.021 \\
\hline Organization & $0.1650^{* * *}$ & 0.001 & 0.0321 & 0.888 \\
\hline Insurance & $0.1425^{* * *}$ & 0.000 & $0.5818^{* * *}$ & 0.000 \\
\hline Plot size & $0.0149 * * *$ & 0.000 & $0.0804 * * *$ & 0.000 \\
\hline July temperature & $-0.0610^{*}$ & 0.064 & & \\
\hline July precipitation & $0.0011^{* * *}$ & 0.000 & & \\
\hline Winter season & $0.1058^{*}$ & 0.071 & & \\
\hline Mig-ag ratio & & & $-0.0110 * *$ & 0.042 \\
\hline$\rho$ (p-value) & \multicolumn{4}{|c|}{$0.7100 * *(0.0108)$} \\
\hline Crop dummies & & & & \\
\hline Observations & \multicolumn{4}{|c|}{1659} \\
\hline
\end{tabular}

Note: ${ }^{* * *}, * *$, and $*$ represent significance at $1 \%, 5 \%$, and $10 \%$ level, respectively. Standard errors are clustered at the household level. The marg. eff. column reports the average partial effects across all individuals in the sample. 
Table 5. Results of Control Function with LPM ${ }^{15}$

\begin{tabular}{|c|c|c|c|c|}
\hline \multirow{2}{*}{ Variable } & \multicolumn{2}{|c|}{ LPM } & \multicolumn{2}{|c|}{ Probit } \\
\hline & Coef. (Marg. eff.) & p-value & Coef. & p-value \\
\hline Rented plot & $-0.5251^{*}$ & 0.054 & & \\
\hline Age & -0.0004 & 0.863 & $0.0218^{* * *}$ & 0.005 \\
\hline Farming experience & -0.0012 & 0.512 & $-0.0122 *$ & 0.081 \\
\hline Risk preference & 0.0386 & 0.241 & 0.0188 & 0.893 \\
\hline Education & $0.0210 * * *$ & 0.000 & $0.0310^{*}$ & 0.091 \\
\hline Number of laborers & $0.0607 * * *$ & 0.000 & -0.0508 & 0.400 \\
\hline Income & 0.0082 & 0.170 & 0.0274 & 0.152 \\
\hline Organization & $0.1427 * *$ & 0.043 & -0.0117 & 0.974 \\
\hline Insurance & $0.1718^{* * *}$ & 0.000 & $0.5829 * * *$ & 0.000 \\
\hline Plot size & $0.0137 * * *$ & 0.003 & $0.0772 * * *$ & 0.000 \\
\hline July temperature & -0.0821 & 0.121 & & \\
\hline July precipitation & $0.0015^{* * *}$ & 0.000 & & \\
\hline Winter season & $0.1696^{* *}$ & 0.030 & & \\
\hline Generalized residual & 0.2293 & 0.109 & & \\
\hline Mig-ag ratio & & & -0.0048 & 0.517 \\
\hline Intercept & 1.9038 & 0.165 & $-2.7877 * * *$ & 0.000 \\
\hline Crop dummies & Yes & & & \\
\hline Observations & & & & \\
\hline
\end{tabular}

Note: $* * *, * *$, and $*$ represent significance at $1 \%, 5 \%$, and $10 \%$ level, respectively. Standard errors are clustered at the household level.

492 significant at the ten percent level. It is noteworthy that the generalized residual term appears

493 insignificant at any significance level but with a very close p-value of 0.109 , which fails to reject

494 the null hypothesis that renting is exogenous, suggesting that at least the endogeneity may not be

495 that apparent in our case. However, it is important to note that one could not fully rely on a

\footnotetext{
15 In an identical model but without exclusion restriction variable (i.e. "mig-ag ratio” is excluded in the probit regression), whose identification of the endogenous rental variable simply relies on the nonlinearity nature of the generalized residual, the coefficient (marginal effect) of the rental dummy is -0.3707 but insignificant with a p-value of 0.16 .
} 
496 marginally insignificant test statistic to claim full exogeneity. ${ }^{16}$ We argue that our control

497 function approach at least mitigated, if not fully addressed, the endogeneity concerns. We also

498 want to caution readers that alternative specifications of our control function approach, using

499 alternative set of instruments such as migrants' income in levels or without any instrumental

500 variables in the first stage, lead to statistically insignificant coefficient for the land tenure

501 variable. This suggests further research is needed to examine the robustness of these results but

502 even in these alternative specifications the coefficient for land tenure on straw retention is still

503 negative.

504 Contrary to the results in the adoption regression, characteristics of the household head, 505 including age and farming experience, appear to play an important role in driving land rental 506 decisions. Higher family education level, higher family income, and purchase of insurance are 507 positively related to the probability of renting more farmland. In addition, the positive and 508 significant coefficient of plot size confirms our conjecture that renters are more likely to rent 509 larger fields or more farmland. The exclusion restriction variable (migrants' income ratio) is 510 negatively significant in the bivariate probit model, which confirms our expectation that 511 households with higher remittances from migrant members are less willing to rent from other 512 contractees. This variable has negative coefficient in the control function approach as well but it 513 is statistically insignificant.

\section{$514 \quad$ 6.3. Discussion}

\footnotetext{
16 We thank an anonymous reviewer for pointing this out.
} 
515 Our empirical results provide evidence that land tenure insecurity, as proxied by rented plots, tend to negatively impact farmers’ decisions to adopt straw retention in China. Combining results

517 of all three regression models, we discover that after dealing with the potential endogeneity 518 issue, there is a dramatic increase in magnitude of the average marginal effect of renting on 519 conservation practice adoption, from about -0.08 in the base model to around -0.50 , which is much higher than that in the existing literature (Soule et al., 2000; Gebremedhin and Swinton, 2003; Kabubo-Mariara et al., 2010; Baumgart-Gets et al., 2012). This increase is intuitive in the 522 sense that the base probit model may be underestimated, either due to renters' self-selection 523 behaviors or omission of some important covariates. More specifically in our data analysis, the omitted unobservables could be positively related to both farmers’ rental decisions and adoption choices. Evidence includes the positive coefficient on the residual term (although insignificant) from the second-stage regressions in two control function models and the positive and significant

$527 \rho$ in the bivariate probit that measures correlation between adoption and renting equations. omitted factors and unfortunately they were not covered in our survey data. ${ }^{17}$ Use of machinery can facilitate straw retention and save laborers to a large extent, so households who own relevant machines, or are able to rent machines from outside supplies, are more likely to adopt straw retention. Meanwhile, machinery availability may further lead to an increased likelihood of

\footnotetext{
17 We thank an anonymous review for pointing out that these two factors may be correlated, though slightly, with the instrument variable, the migrants' income ratio. We acknowledge that the constructed ratio variable may not fully solve the endogeneity of the rental dummy. While in this sense, the use of control function method could mitigate the endogeneity problem to a large extent.
} 
boost grain production. ${ }^{18}$ Although these subsidies do not directly target conservation, it is

reasonable to infer that households receiving more subsidies are less vulnerable to uncertain

short-term profit loss from adopting straw retention. Moreover, households residing in areas

where the subsidies are available are more willing to grow crops and thus more likely to rent

more farmland simply to increase income. Recent studies in China also support the claim that

machinery use and subsidies play an important and positive role in inducing straw retention

behaviors, and their effects warrant further research. ${ }^{19}$

\footnotetext{
${ }^{18}$ Four categories of subsidies include direct grain subsidy, superior grain varieties subsidy, agricultural machinery and tools subsidy, and general agricultural suppliers subsidy. Unlike the straw retention subsidy that is about to take effect in recent years, these subsidies have been available since 2004 in most areas of China.

19 See Qi et al. (2016) and Tong and Liu (2017) as examples.

20 To test the potential effects of contract type and lease term on adoption, we have also run several probit regressions for only the 155 renters in our sample. Results are reported in Table A.1 in Appendix 2, where we list four specifications with column (1) the base model and columns (2)-(4) with one or two of the contract variables augmented. However, results reveal that neither of the two contract variables is significant in any specification. Therefore, we are unable to identify the effect of contract type and renewal frequency in this study.
} 


\section{Concluding Remarks}

550

551

552

553

554

555

556

557

558

559

560

561

562

563

564

565

566

567

568

Based on data from a 2016 farmer household survey in Henan Province in central China, we apply several probit regressions, including a bivariate probit model and a control function method, to examine how land tenure arrangements especially land rental decisions affect the probability of adopting crop straw retention. We employ an instrument that relies on the remittance income from household members who migrate to cities to address the potential endogeneity of the land tenure variable. Empirical results show that farmer households are more likely to adopt straw retention after harvest on own-contracted than rented plots, which is consistent with previous literature that shows insecure land tenure often hinders adoption of conservation practices. This study provides some of the first evidence in assessing the negative impact of land tenure insecurity on the adoption of a long-term land improvement practice, straw retention.

Our findings have important and valuable policy implications. The Chinese government is currently encouraging participation of market-based rural land transfer as an alternative to committee-intervening land reallocation to improve agricultural production efficiency. However, our results imply that more careful deliberation or monitoring is warranted regarding the potential impediments to less-sustainable farming practices on the growing acres of rented grounds. Our results also suggest that the air quality and other environmental benefits from encouraged straw retention could be impacted without further efforts to boost adoption on rented land. Due to less secure land tenure, farmers on rented plots may have lower incentives to adopt 
conservation practices, causing environmental problems such as more PM 2.5 emissions from straw burning and more severe soil degradation. Improving the land tenure security, especially for rented plots, may be one effective measure. For instance, the government could regulate the rental market by enforcing the use of a more stable and formal written contract, which incorporates specific requirements on conservation practices and residue management. On the other hand, it may also be helpful to extend the current range of land contract rights transfer from within-village to cross-village or within-township, in order to allow farmer households to own more contracted land and stimulate long-run land improvements.

The importance of our findings notwithstanding, they are limited by the fact that some of important factors such as availability of machinery and agricultural subsidies were not covered in our survey. Moreover, the effects of different aspects of tenure security need further investigation. For instance, the duration of tenure, another important dimension of tenure security either for own-contracted or rented land, may also play a role in affecting the adoption rate. In addition, with a panel dataset, one can examine whether the adoption rate of straw retention varies over time under different policy scenarios, such as varying strictness on restricting the burning of straws and the forthcoming straw retention subsidy. It is possible that the higher adoption rate is mainly due to the prohibition of straw burning.

Another caveat is that our empirical results may not always be robust in terms of the significance and magnitude of the land rental variable when we rely on alternative instruments in both the biprobit and control function models. For instance, using migrant income in levels or 
589 relative share of migrants' income could lead to differing estimated marginal effects of rental 590 ranging from 38 percent to 51 percent. However, it is important to note that the rental variable 591 has been shown consistently to negatively impact the adoption of straw retention, even in cases 592 of statistical insignificance. This could result from our data limitation of only relying on one 593 year's data, or lack of information about some important omitted factors, which suggests 594 additional research to examine the role of land tenure in conservation practice adoptions. 595 596

597 Acknowledgements

598 The authors are grateful to Otavio Bartalotti, Minghao Li, Bo Zhang, and Doug Wrenn for 599 helpful discussions and two anonymous referees of this journal for their thoughtful comments on 600 an earlier draft. This research was supported by Science Foundation of China University of 601 Petroleum, Beijing (No. 2462017YJRC049) and (No. 2462017YJRC007), and the National 602 Natural Science Foundation of China (No. 71703166).

603 


\section{References}

Altonji, J.G., T.E. Elder, C.R. Taber. 2005. “An Evaluation of Instrumental Variable Strategies for Estimating the Effects of Catholic Schooling." The Journal of Human Resources 40(4): 791-821.

Baumgart-Getz, A., L.S. Prokopy, and K. Floress. 2012. "Why Farmers Adopt Best Management Practice in the United States: A Meta-analysis of the Adoption Literature.” Journal of Environmental Management 96(1): 17-25.

Benjamin, D. and L. Brandt. 2002. "Property Rights, Labour Markets, and Efficiency in a Transition Economy: the Case of Rural China.” Canadian Journal of Economics 35(4): $689-716$.

Brandt, L., J. Huang, G. Li, and S. Rozelle. 2002. "Land Rights in Rural China: Facts, Fictions and Issues.” The China Journal 47: 67-97.

Cai, Y., H. Qiu, Z. Xu. 2011. Evaluation on Potentials of Energy Utilization of Crop Residual Resources in Different Regions of China [Zhong Guo Ge Qu Yu Jie Gan Zi Yuan Ke Neng Yuan Hua Li Yong De Qian Li Fen Xi]. Journal of Natural Resources 26(10): 1637 - 1646. (In Chinese)

Carvalho, J., R. Nogueirol, L. Menandro, R. Bordonal, C. Borges, H. Cantarella, H. Franco. 2017. “Agronomic and Environmental Implications of Sugarcane Straw Removal: A Major Review.” Global Change Biology Bioenergy 9: 1181-1195.

Chen, J., Li, C., Ristovski, Z., Milic, A., Gu, Y., Islam, M.S., Wang, S., Hao, J., Zhang, H., He, C., Guo, H., Fu, H., Miljevic, B., Morawska, L., Thai, P., LAM, Y.F., Pereira, G., Ding, A., Huang, X., Dumka, U.C. 2017. “A review of biomass burning: Emissions and impacts on air quality, health and climate in China.” Science of the Total Environment 579: 10001034. 
China, People’s Republic of, Ministry of Agriculture. 2014. 26\% Contracted Land Has Been Transferred, Ministry of Agriculture Required No Forced Commands [Quan Guo 26\% Cheng Bao Di Yi Liu Zhuan, Nong Ye Bu Yao Qiu Bu Neng Gao Qiang Po Ming Ling]. Available at http://news.xinhuanet.com/fortune/2014-02/23/c_119460477.htm. (in Chinese)

China, People's Republic of, Ministry of Agriculture. 2015. The Transferred Land Has Accounted for More Than 30\% of the Total Contracted Land [Quan Guo Geng Di Liu Zhuan Mian Ji Zhan Zong Cheng Bao Geng Di Bi Zhong Chao Guo San Cheng]. Available at http://news.xinhuanet.com/fortune/2015-08/27/c_1116397151.htm. (in Chinese)

China, People’s Republic of, Ministry of Agriculture. 2016. Ministry of Agriculture: The Transferred Land Areas Have Been 447 Million Mu by the End of Last Year [Nong Ye Bu: Jie Zhi Qu Nian Di, Quan Guo Jia Ting Cheng Bao Geng Di Liu Zhuan Mian Ji 4.47 Yi Mu]. Available at http://www.chinanews.com/cj/2016/08-10/7967918.shtml. (in Chinese)

Dinardo-Miranda, L.L., J.V. Fracasso. 2013. “Sugarcane Straw and the Populations of Pests and Nematodes.” Scientia Agricola 70(5): 305-310.

Deininger, K. and S. Jin. 2005. “The Potential of Land Rental Markets in the Process of Economic Development: Evidence from China.” Journal of Development Economics 78(1): 241-270.

Feder, G., T. Onchan, Y. Chalamwong, and C. Hongladarom. 1988. Land Policies and Farm Productivity in Thailand. Baltimore and London: Johns Hopkins University Press for the World Bank.

Fox, G., A. Weersink, G. Sarwar, S. Duff, and B. Deen. 1991. "Comparative Economics of Alternative Agricultural Production Systems: A Review.” Northeastern Journal of Agricultural and Resource Economics 20(1): 124-142. 
Fraser, E.D.G. 2004. “Land Tenure and Agricultural Management Soil Conservation on Rented and Owned Fields in Southwest British Columbia.” Agriculture and Human Values 21(1): 73-79.

Fu, L., S. Wang, Z. Wu, S. Liu, S. Yang, and R. Zhang. 2017. “Estimation of Air Pollutant Emissions from Straw Residues Open Burning in Henan Province [He Nan Sheng Jie Gan Lu Tian Fen Shao Da Qi Wu Ran Wu Pai Fang Liang De Gu Suan Yu Fen Xi].” Journal of Agro-Environment Science, 36(4): 808-816. (in Chinese)

Gourieroux, C., A. Monfort, E. Renault, A. Trognon. 1987. “Generalised Residuals.” Journal of Econometrics 34(1-2): 5-32.

Gebremedhin, B. and S.M. Swinton. 2003. "Investment in Soil Conservation in Northern Ethiopia: The Role of Land Tenure Security and Public Programs.” Agricultural Economics 29(1): 69-84.

Hu, W. 1997. "Household Land Reform in China: Its Impact on Farming Land Use and Agro-environment.” Land Use Policy 14(3): 175-186.

Huang, S., Y. Zeng, J. Wu, Q. Shi, and X. Pan. 2013. “Effect of Crop Residue Retention on Rice Yield in China: A Meta-analysis.” Field Crops Research 154: 188-194.

Jacoby, H.G., G. Li, and S. Rozelle. 2002. "Hazards of Expropriation: Tenure Insecurity and Investment in Rural China.” The American Economic Review 92(5): 1420-1447.

Kabubo-Mariara, J., V. Linderhof, and G. Kruseman. 2010. “Does Land Tenure Security Matter for Investment in Soil and Water Conservation? Evidence from Kenya.” African Journal of Agricultural and Resource Economics 4(2): 123-139.

Knowler, D. and B. Bradshaw. 2007. “Farmers’ Adoption of Conservation Agriculture: A Review and Synthesis of Recent Research.” Food policy 32(1): 25-48. 
Krusekopf, C.C. 2002. "Diversity in Land-tenure Arrangements under the Household Responsibility System in China.” China Economic Review 13(2): 297-312.

Kurkalova, L., C. Kling, and J. Zhao. 2006. "Green Subsidies in Agriculture: Estimating the Adoption Costs of Conservation Tillage from Observed Behavior.” Canadian Journal of Agricultural Economics 54(2): 247-267.

Lee, L.K. and W.H. Stewart. 1983. "Landownership and the Adoption of Minimum Tillage.” American Journal of Agricultural Economics 65(2): 256-264.

Leight, J. 2016. "Reallocating Wealth? Insecure Property Rights and Agricultural Investment in Rural China.” China Economic Review 40: 207-227.

Liu, S., M. Carter, and Y. Yao. 1998. "Dimension and Diversity of Property Right in Rural China: Dilemmas on the Road to Further Reform.” World Development 26(10): 1789-1806.

Liu, H. and Q. Huang. 2013. "Adoption and Continued Use of Contour Cultivation in the Highlands of Southwest China.” Ecological Economics 91: 28-37.

Lu, F. 2015. "How Can Straw Incorporation Management Impact on Soil Carbon Storage? A Meta-analysis.” Mitigation and Adaptation Strategies for Global Change 20(8): 15451568.

McConnell, K.E. 1983. “An Economic Model of Soil Conservation.” American Journal of Agricultural Economics 65(1): 83-89.

Peng, L., Q. Zhang, K. He. 2016. "Emission inventory of atmospheric pollutants from open burning of crop residues in China based on a national questionnaire [Ji Yu Diao Cha De Zhong Guo Jie Gan Lu Tian Fen Shao Wu Ran Wu Pai Fang Qing Dan].” Research of Environmental Sciences 29(8): 1109-1118. (in Chinese) 
Pittelkow, C.M, X. Liang, B.A. Linquist, K.J. van Groenigen, J. Lee, M.E. Lundy, N. van Gestel, J. Six, R.T. Venterea, and C. van Kessel. 2015. "Productivity Limits and Potentials of the Principles of Conservation Agriculture.” Nature 517(7534): 365-368.

Qi, J., L. Zhu, L. Chen, Q. Li. 2016. “Research on the farmers' behavior of straw processing in Jiangsu, Zhejiang and Anhui [Su Zhe Wan Nong Hu Jie Gan Chu Li Xing Wei Fen Xi].” Resources Science 38(6): 1099-1108. (in Chinese)

Rivers, D., Q.H. Vuong. 1988. “Limited Information Estimators and Exogeneity Tests for Simultaneous Probit Models.” Journal of Econometrics 39: 347-366.

Salant, S.W. and X. Yu. 2016. “Forest Loss, Monetary Compensation, and Delayed Re-planting: The Effects of Unpredictable Land Tenure in China.” Journal of Environmental Economics and Management 78: 49-66.

Shon, Z.H. 2015. "Long-term variations in PM 2.5 emission from open biomass burning in Northeast Asia derived from satellite-derived data for 2000-2013.” Atmospheric Environment 107: 342-350.

Soule, M.J., A. Tegene, and K.D. Wiebe. 2000. "Land tenure and the adoption of conservation practices.” American Journal of Agricultural Economics 82(4): 993-1005.

Tan, S., N. Heerink, and F. Qu. 2006. "Land Fragmentation and Its Driving Forces in China.” Land Use Policy 23(3): 272-285.

Tao, J., L. Zhang, G. Engling, R. Zhang, Y. Yang, J. Cao., C. Zhu, Q. Wang, and L. Luo. 2013. "Chemical Composition of PM2.5 in an Urban Environment in Chengdu, China: Importance of Springtime Dust Storms and Biomass Burning.” Atmospheric Research 122: 270-283.

Tong, H., W. Liu. 2017. “Empirical Study on Factors of Farmers’ Straw Returning Technology Adoption: Based on Survey Data of 311 Households [Nong Hu Jie Gan Huan Tian Ji Shu 
Cai Na Xing Wei Ying Xiang Yin Su Shi Zheng Yan Jiu: Ji Yu 311 Hu Nong Hu De Diao Cha Shu Ju].” Rural Economy 4: 108-114. (in Chinese)

Vella, F. 1998. "Estimating Models with Sample Selection Bias: A Survey.” The Journal of Human Resources 33(1): 127-169.

Wang, J., J. Huang, L. Zhang, S. Rozelle, and H.F. Farnsworth. 2010. "Why is China's Blue Revolution So Blue? The Determinants of Conservation Tillage in China.” Journal of Soil and Water Conservation 65(2): 113-129.

Wang, J., X. Wang, M. Xu, G. Feng, W. Zhang, and C. Lu. 2015. “Crop Yield and Soil Organic Matter after Long-term Straw Return to Soil in China." Nutrient Cycling in Agroecosystems 102(3): 371-381.

Wooldridge, J.M. 2010. Economic Analysis of Cross Section and Panel Data, 2nd. ed. Cambridge MA: The MIT Press.

Wooldridge, J.M. 2015. “Control Function Methods in Applied Econometrics.” Journal of Human Resources 50(2): 420-455.

Ye, J. 2015. "Land Transfer and the Pursuit of Agricultural Modernization in China.” Journal of Agrarian Change 15(3): 314-337.

Zhang, G., F. Lu, H. Zhao, G. Yang, X. Wang, Z. Ouyang. 2017. "Residue usage and farmers' recognition and attitude toward residue retention in China’s croplands [Wo Guo Nong Zuo Wu Jie Gan Zi Yuan Hua Li Yong Xian Zhuang Ji Nong Hu Dui Jie Gan Huan Tian De Ren Zhi Tai Du].” Journal of Agro-Environment Science 36(5): 981-988. (in Chinese)

Zhang, Y., X. Wang, T. Glauben, and B. Brümmer. 2011. "The Impact of Land Reallocation on Technical Efficiency: Evidence from China.” Agricultural Economics 42(4): 495-507. 
744 Zhang, W., R.S. Wilson, E. Burnett, E.G. Irwin, J.F. Martin. 2016. "What Motivates Farmers to 745 Apply Phosphorus at the "Right" Time? Survey Evidence from the Western Lake Erie 746 Basin.” Journal of Great Lakes Research 42(6): 1343-1356.

747 
Appendix 1: Translated Version of Survey Questionnaire

\section{Survey on Farmers' Planting Behavior in Henan Province 2015}

City

County

Town

Name of interviewee Contact number
Village Date Name of interviewer

\begin{tabular}{|c|c|c|c|c|c|c|c|c|c|c|}
\hline \multirow{2}{*}{$\begin{array}{l}\text { A2 Land area for } \\
\text { each property } \\
\text { type (Mu) } \\
\text { Plot Index }\end{array}$} & \multicolumn{4}{|c|}{ Own-contracted } & \multicolumn{4}{|c|}{ Rented-in } & \multicolumn{2}{|c|}{ Trusteeship_ } \\
\hline & $\mathrm{X} 1$ & $\mathrm{X} 2$ & X3 & $\mathrm{X} 4$ & Y1 & Y2 & Y3 & Y4 & $\mathbf{Z 1}$ & $\mathbf{Z 2}$ \\
\hline \multicolumn{11}{|l|}{ A3 Plot area $(\mathrm{Mu})$} \\
\hline A4 Contract type & NA & NA & NA & NA & & & & & NA & NA \\
\hline A5 Lease term (ys) & NA & NA & NA & NA & & & & & NA & NA \\
\hline \multicolumn{11}{|c|}{ Season 1: Autumn } \\
\hline \multicolumn{11}{|l|}{ A6a Crop } \\
\hline \multicolumn{11}{|l|}{ A7a Straw treatment } \\
\hline \multicolumn{11}{|l|}{$\begin{array}{c}\text { A8a Reasons for SR } \\
\text { adoption }\end{array}$} \\
\hline \multicolumn{11}{|l|}{$\begin{array}{c}\text { A9a Reasons for SR } \\
\text { non-adoption }\end{array}$} \\
\hline \multicolumn{11}{|c|}{ Season 2: Winter-Summer } \\
\hline \multicolumn{11}{|l|}{ A6b Crop } \\
\hline \multicolumn{11}{|l|}{ A7b Straw treatment } \\
\hline \multicolumn{11}{|l|}{$\begin{array}{l}\text { A8b Reasons for SR } \\
\text { adoption }\end{array}$} \\
\hline $\begin{array}{c}\text { A9b Reasons for SR } \\
\text { non-adoption }\end{array}$ & & & & & & & & & & \\
\hline
\end{tabular}

A. On-farm Operation of Tillage and Straw Return in 2015

A1 In 2015, total areas of family cultivable land is Mu; \# of plots ; the area of the biggest plot is $\mathrm{Mu}$.

A2 Land area for each property (Mu)

Note:

1. Plot division: Plots with the same property type and identical planted crops for both seasons is treated as ONE plot (no matter whether the plot(s) is(are) connected).

2. A4 Contract type: $1=$ oral; $2=$ written.

3. A6 Crop: $0=$ not planted; $1=$ wheat; $2=$ corn; $3=$ =rice; $4=$ soybean; $5=$ peanut; $6=$ cotton; $7=$ inter-panting; $8=$ others.

4. A7 Straw treatment (multiple choices):1=straw return (SR); $2=$ burn; $3=$ use as feed; $4=$ =use as fuel; $5=$ for 
sale; 6=discard; 7=no straw ; 8=others.

5. A8 Reasons for SR adoption (multiple choices): 1=soil improvement; $2=$ fertilizer saving; 3=policy factors; $4=$ increasing production/income; $5=$ unable to handle; $6=$ environmental protection; $7=$ others.

6. A9 Reasons for SR non-adoption (multiple choices): 1=affecting planting; $2=$ cost saving; $3=$ policy factors; $4=$ =lack of laborers; $5=$ =lack of machinery; $6=$ feeling troublesome; $7=$ avoiding infected by pests and diseases; 8=others.

\section{B01 Purpose of farming ( )}

\section{B. Production and Operation of Crop Planting in 2015}

$1=$ to increase income; $2=$ to hold land property; $3=$ to eat; $4=$ without other job opportunities if not farming; $5=$ =scale management; $6=$ others.

B02 What do you think is the most currently necessary technology for farming ( ) $1=$ new varieties; $2=$ new fertilizers; $3=$ new pesticides; 4=new machinery; 5=new irrigation facilities; $6=$ others.

B03 What do you think is the harm of excessive use of chemical fertilizer and pesticide ( )

1=causing residues harmful to human; $2=$ =soil compaction; $3=$ waste of resources; $4=$ =pollution; $5=$ =have to gradually increase the input of chemical fertilizer and pesticide; $6=$ reducing soil fertility; $7=$ no harm; 8=others.

\begin{tabular}{|c|c|c|c|c|c|}
\hline Crop index & $\begin{array}{c}\text { W1 } \\
\text { Wheat }\end{array}$ & $\begin{array}{l}\text { W2 } \\
\text { Corn }\end{array}$ & $\begin{array}{c}\text { W3 } \\
\text { Rice }\end{array}$ & $\begin{array}{c}\text { W4 } \\
\text { Soybean }\end{array}$ & $\begin{array}{c}\text { W5 } \\
\text { Other }(\square)\end{array}$ \\
\hline B1 Sown area (Mu) & & & & & \\
\hline B2 Yield (kg/Mu) & & & & & \\
\hline B3 Sale price $(¥ / \mathrm{kg})$ & & & & & \\
\hline B4 Seed price ( $¥ / \mathrm{Mu}$ ) & & & & & \\
\hline B5a Base fertilizer cost ( $¥ / \mathrm{Mu})$ & & & & & \\
\hline B5b Top-dressing cost ( $¥ / \mathrm{Mu})$ & & & & & \\
\hline B6 Pesticide cost ( $¥ / \mathrm{Mu})$ & & & & & \\
\hline B7 Irritation cost ( $¥ / \mathrm{Mu})$ & & & & & \\
\hline B8 Machinery cost ( $¥ / \mathrm{Mu})$ & & & & & \\
\hline B9 Labor cost ( $¥ / \mathrm{Mu})$ & & & & & \\
\hline B10 Other cost ( $¥ / \mathrm{Mu})$ & & & & & \\
\hline
\end{tabular}

Note:

1. In this table, only record crops that involve straw treatment; for those without straws (e.g. watermelon, pepper, vegetables, etc.), no need to fill in.

2. B9 Labor cost: If the household hires workers at any part of the cost link (B5 - B8), count the cost as labor cost and fill it in B9, and leave the corresponding blank (B5 - B8) empty. 


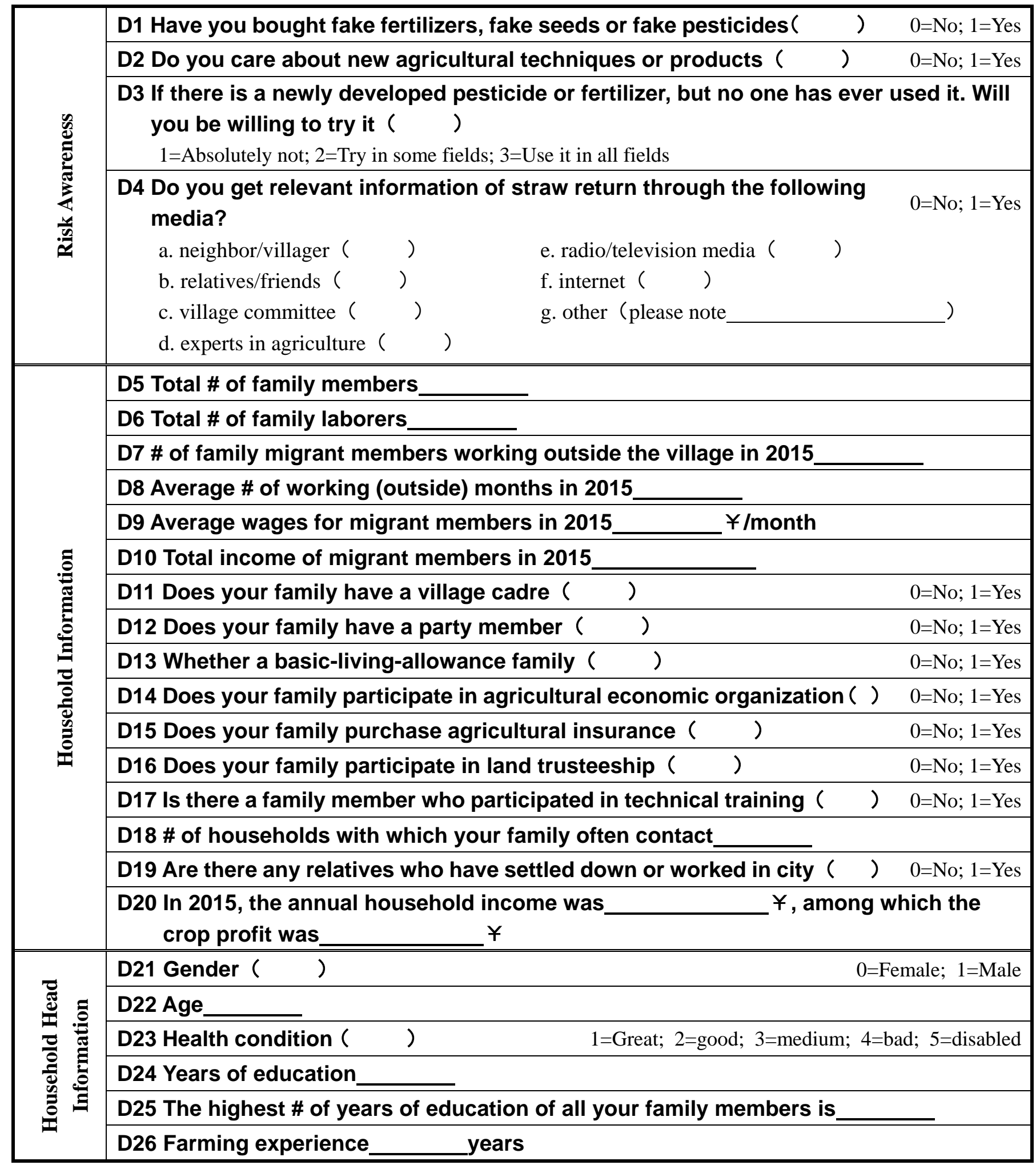




\section{Appendix 2: Additional Regression Results}

791 Table A.1 Probit Regression Results for Renters Only (Dependent: adoption=1)

\begin{tabular}{ccccc}
\hline Variable & $(1)$ Base & $(2)$ & $(3)$ & $(4)$ \\
\hline Age & 0.0297 & 0.0289 & 0.0280 & 0.0276 \\
Farming experience & -0.0155 & -0.0150 & -0.0126 & -0.0124 \\
Risk preference & 0.3962 & 0.4074 & 0.4172 & 0.4215 \\
Education & $0.1200^{* *}$ & $0.1215^{* *}$ & $0.1156^{* *}$ & $0.1165^{* *}$ \\
Number of laborers & $0.4566^{* * *}$ & $0.4500^{* * *}$ & $0.4702^{* * *}$ & $0.4654^{* * *}$ \\
Income & -0.0058 & -0.0039 & -0.0294 & -0.0269 \\
Organization & 0.8375 & 0.8453 & 0.8886 & 0.8883 \\
Insurance & 0.3692 & 0.3212 & 0.3770 & 0.3508 \\
Plot size & 0.0118 & 0.0093 & 0.0071 & 0.0054 \\
July temperature & 0.7747 & 0.7950 & 0.7542 & 0.7644 \\
July precipitation & $0.0049^{* *}$ & $0.0050^{* *}$ & $0.0044^{* *}$ & $0.0045^{* *}$ \\
Winter season & 0.0772 & 0.0609 & 0.0886 & 0.0784 \\
Contract type & & 0.3711 & & 0.2126 \\
Term of lease & & & 0.1109 & 0.1058 \\
Intercept & $-25.6801^{* *}$ & $-26.2282^{* *}$ & $-24.9656^{*}$ & $-25.2419^{* *}$ \\
Crop dummies & & & & \\
Observations & Yes & Yes & Yes & Yes \\
\hline
\end{tabular}

Note: ${ }^{* * *}, * *$, and $*$ represent significance at $1 \%, 5 \%$, and $10 \%$ level, respectively. Standard errors are clustered at the household level. "Contract type" is a dummy equal to unity if the lease is written (oral otherwise). "Term of lease" is a variable indicating how many years the lease covers. 